\title{
Una plaquita de hueso con esfinge procedente de Segobriga (Cabeza de Griego, Saelices, Cuenca). Paralelos y cronología
}

\author{
A bone plate with a sphinx from Segobriga (Cabeza de Griego, Saelices, \\ Cuenca). Parallels and chronology
}

Rosario Cebrián Fernández, marcebri@ucm.es, https://orcid.org/0000-0002-5560-1191, Universidad Complutense de Madrid, España

\begin{abstract}
Resumen
Entre los materiales arqueológicos recuperados en la campaña de excavaciones realizada en Segobriga en el año 1982 se encuentra una plaquita rectangular de hueso con la representación de una esfinge. Procede de un estrato fechado en época tardoantigua donde esta plaquita constituye un elemento aislado de la caja que originalmente decoró. Las similitudes estilísticas de la pieza con la placa con esfinge de Ibiza aconsejan atribuir su origen a la esfera artística etrusca. Sin embargo, la esfinge segobrigense tiene un aire más arcaico, más cercano a la técnica figurativa jonia/oriental que, desde un punto de vista cronológico, admite fecharla en el último cuarto del siglo VI a. C o inicios de la siguiente centuria. La pieza debe añadirse a la lista de materiales de la Edad del Hierro documentados en los trabajos arqueológicos en Segobriga o procedentes de hallazgos aislados, que confirma la existencia de una población prerromana asentada sobre el cerro de Cabeza de Griego desde, al menos, el siglo VI a. C. La presencia de este objeto junto a otros, como un colgante fálico de origen púnico y un aryballos de vidrio del ámbito griego, testimonia la llegada de productos de lujo destinados a la aristocracia local asentada sobre este castro de la Celtiberia. En particular, la plaquita con esfinge complementa el mapa de distribución de las importaciones de kibotia - etrusca o griegaen el extremo occidental del Mediterráneo a partir del siglo VI a. C., donde son escasos este tipo de objetos, especialmente, en yacimientos del interior peninsular.
\end{abstract}

Palabras clave. Esfinge; objeto de hueso; kibotia etrusca; taller griego; Segobriga.

\begin{abstract}
A rectangular bone plaque with the representation of a sphinx was found during the archaeological excavation campaign carried out in Segobriga in 1982. It was found in a layer dated to the Late Antique period, where this small artefact was found apart from the box it originally decorated. The stylistic similarities between this piece and the sphinx plaque from Ibiza suggest an Etruscan artistic origin. However, the sphinx from Segobriga seems to be more archaic, closer to the Ionian/Oriental figurative technique which, from a chronological point of view, would date it to the last quarter of the 6th century $\mathrm{BC}$ or the beginning of the following century. This piece should be added to the list of Iron Age materials documented either by the archaeological work carried out in Segobriga or from isolated finds, which confirm the existence of a pre-Roman settlement on the Cabeza de Griego hill from at least the 6th century BC. The presence of this object along with others, such as a phallic pendant of Punic origin and a glass aryballos from the Greek area, is testimony to the arrival of luxury products destined for the local aristocracy settled on this Celtiberian hill fort. The sphinx plaque complements the distribution map of kibotia imports - Etruscan or Greek - in the western end of the Mediterranean from the 6th century BC onwards, where this type of object is scarce, especially in sites in the interior of the Iberian Peninsula.
\end{abstract}

Keywords. Sphinx; bone object; Etruscan kibotia; Greek workshop; Segobriga. 


\section{INTRODUCCIÓN}

El examen de los materiales arqueológicos procedentes de las campañas de excavaciones realizadas en Segobriga en el período 1972-1982 ha permitido localizar en el almacén del Museo una placa inédita, tallada en hueso, con representación de una esfinge. El lugar de hallazgo corresponde al área urbana situada inmediatamente al sur del teatro dentro del recinto amurallado, que fue objeto de intervención arqueológica en 1982. De aquellas excavaciones nunca se llegaron a publicar sus resultados pero sabemos que, mientras se ultimaban las excavaciones en el anfiteatro (área 1), se planificó una campaña en la gran plataforma que se extendía al mediodía del edificio para espectáculos teatrales. Esta campaña de excavación se desarrolló en el entorno de las termas del teatro (áreas 2 y 3), en el criptopórtico adosado a la muralla (área 4) y en el área abierta adyacente (área 5), interpretada entonces como una gran palestra integrada en un gymnasium del conjunto termal (Almagro Basch, 1983: 72; Almagro-Gorbea y Abascal, 2008).
La pieza fue localizada en un estrato fechado en época tardorromana por los materiales asociados. El único dato sobre su procedencia exacta es la referencia de su signatura, que indica que se encontró en el otoño de 1982 en el sector 14 del área 5 (Fig. 1). La reanudación de las excavaciones en esta zona de la ciudad en el año 2009 confirmaron su ocupación desde mediados del siglo I a. C. por viviendas cimentadas en la roca y levantadas con zócalos de mampostería, alzados de adobe y cubiertas de madera con entramado vegetal (Abascal et al., 2010: 17-20), mientras al oriente de estas casas en la parte más alta se identificó un pequeño templo o sacellum de estructura in antis (Cebrián, 2017: 480-482). La reestructuración de esta zona urbana adscrita cronológicamente al oppidum stipendiarium de Segobriga se llevó a cabo en época tiberiana en el marco del proyecto de monumentalización de la ciudad. Aquel espacio sacro quedó dentro de un complejo de plaza con pórticos/cryptoporticus, que amortizó las estructuras domésticas preexistentes, cuyos paralelos se encuentran en los conjuntos religiosos centroitálicos

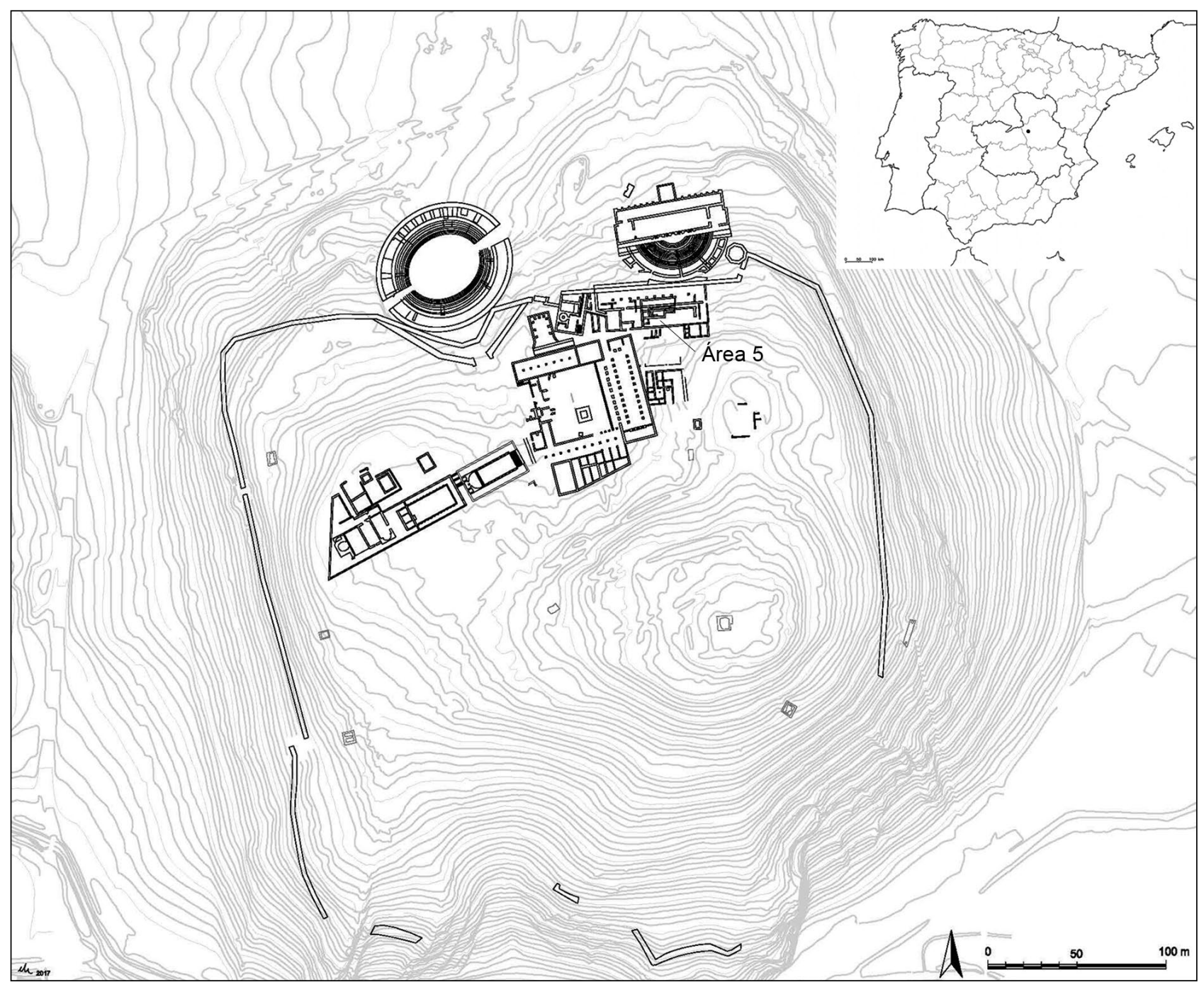

Figura 1: Situación de Segobriga en relación a la península ibérica y área del yacimiento arqueológico donde se halló la plaquita de hueso con representación de una esfinge en las excavaciones efectuadas en 1982. (Imagen: equipo de investigación de Segobriga) 
de época tardorrepublicana. Esta nueva plaza conectaba con el teatro de lo que puede deducirse un mismo proyecto constructivo relacionado con la difusión del culto imperial a partir de las evidencias materiales (Cebrián, 2021: 315-320). Sucesivas reformas acometidas respectivamente en épocas flavia y severa ampliaron el espacio disponible de las termas y consolidaron su estructura. Finalmente, se produjo una paulatina reocupación doméstica y reutilización de las estructuras precedentes en época tardorromana y visigoda hasta su abandono definitivo en época medieval cristiana (Abascal et al., 2010: 44-64).

El proceso constructivo del nuevo marco urbano monumental construido a partir de $c a .15$ a. C., coincidiendo con la obtención del estatus municipal de Segobriga, explica la ausencia de niveles arqueológicos del asentamiento celtibérico. Su transformación en una civitas romana, emplazada sobre el cerro denominado Cabeza de Griego, implicó una profunda reforma urbanística con grandes aterrazamientos y la destrucción y terraplenado de las estructuras anteriores, aunque la secuencia ocupacional del yacimiento arqueológico evidencia la existencia de un núcleo de población prerromano desde el siglo VI a.C. (Lorrio, 2012: 237-240).

Un lote de cerámicas a mano aparecido en los rellenos del desnivel de la roca en el interior del criptopórtico norte del foro puede vincularse al castrum originario (Almagro-Gorbea y Lorrio, 2006-2007: 152-154). A la vez que otros materiales prueban un comercio de importación de productos suntuarios llegados desde el Mediterráneo a partir del siglo VI a. C. (Lorrio, 2007), donde podría incluirse la placa de hueso que presentamos, tomando en consideración los paralelos tipológicos-estilísticos y estilísticos-formales de las placas de revestimiento de kibotia ${ }^{1}$ etrusca (Huls, 1957; Martelli, 1985) señalados para los escasísimos ejemplares procedentes de la península ibérica e Ibiza (Aubet, 1973; Roldán Gómez, 1995-1996; Jiménez Ávila y Barrientos, 2018: 220-221). La representación de la esfinge segobrigense parece encontrarse más próxima al clasicismo griego por el peinado, recogido en la nuca, que $a$ priori la aleja del quehacer de taller y artesanos etruscos. Mientras el tratamiento de su cuerpo, dotado de un número elevado de ubres — polymaste-, alado también admite su adscripción cronológica a partir del período helenístico y, sobre todo, romano (GaggadisRobin, 2009: 463), aun estando presente puntualmente en el ámbito etrusco (Martelli, 1985: 216, fig. 32b y c).

En la problemática de la determinación del lugar de fabricación de la placa de Segobriga entra en juego otra consideración relacionada con el hallazgo de piezas, de cronología claramente anterior, en ajuares funerarios de

1. El término griego kibôtos designa una caja o cofre destinada a conservar diversos objetos, entre ellos, útiles, provisiones, plata o documentos. El diminutivo kibotion refiere a una caja de pequeño tamaño, principalmente, para guardar joyas. Sobre los cofres en el mundo griego, Brümmer, 1985: 1-168. enterramientos altoimperiales, que han sido interpretados como objetos de colección (Feugère, 1989: 59). Esta explicación podría ser válida para un aryballos de vidrio polícromo del ámbito mediterráneo (Lorrio, 2007: 271-272, fig. 5.19), conocido por las excavaciones de R. García Soria y P. Quintero en Segobriga, que fueron llevadas a cabo en el último tercio del siglo XIX. La revisión de la procedencia de estos objetos por A. Lorrio y M. ${ }^{a}$ D. Sánchez de Prado (2002) concluyó que debía adscribirse a la fase de la Edad del Hierro de la necrópolis Haza del Arca de Uclés, donde también aquellos habían realizado trabajos arqueológicos a partir de 1875. El aryballos, según las noticias de P. Quintero (1913: 119-121, n. ${ }^{\circ}$ 2), se encontró en el interior de una urna de vidrio protegida por una cista de plomo, ambas alojadas en un bloque paralelepípedo de piedra, en una tierra de labor al oriente del cerro de Cabeza de Griego. Los datos aportados sugieren su descubrimiento en una necrópolis de incineración de época julioclaudia, donde el aryballos fue un objeto personal del difunto-a, de probada antigüedad (Lorrio y Sánchez de Prado, 2002: 174-177).

En lo que a su cronología se refiere, la imagen de la esfinge estuvo muy difundida por el Mediterráneo desde el inicial modelo egipcio hasta llegar a su representación clásica, con cuerpo felino y rostro humano, en Grecia e Italia Central (Sciacca, 2013) y, más tarde, en Roma (Oenbrick, 2005), lo que no ayuda a la hora de adscribir culturalmente nuestra pieza. Por otro lado, la esfinge segobrigense no se encontró en su contexto primario, es decir, cuando formó parte de la decoración de una caja sino secundario, cuando era un objeto aislado $\mathrm{y}$, por tanto, no resulta útil la datación proporcionada por los materiales que la acompañan.

Estas incertidumbres suponen el punto de partida para alcanzar el encuadre cronológico de la placa de Segobriga dentro de la amplia producción de numerosos objetos de la vida cotidiana, fabricados en marfil y hueso y destinados a la decoración de mobiliario, entre los que se encuentran placas de revestimiento de cofres de madera para uso cosmético, que fueron producidos por talleres de Grecia, Italia, Asia Menor y Alejandría entre los siglos VI a. C. y el II d. C. (Barner, 1982: 62-72).

\section{DESCRIPCIÓN DE LA PLACA}

La pieza corresponde a una placa de revestimiento rectangular, de $6,9 \mathrm{~cm}$ de longitud y $0,3 / 0,5 \mathrm{~cm}$ de grosor (n. ${ }^{\circ}$ de inv.: 82-A5-S14-094). No se ha conservado la esquina superior izquierda correspondiente al enmarque. Está fragmentada por su parte inferior, perdiendo los detalles del cuerpo de la esfinge, abdomen y cuartos traseros del animal y del marco moldurado. La altura conservada es de $2,6 \mathrm{~cm}$. Presenta una perforación circular, de 0,3 cm de sección, en la parte izquierda de la cara frontal. Pudo estar destinada a la sujeción de la pieza al armazón de madera de la caja que decoró 

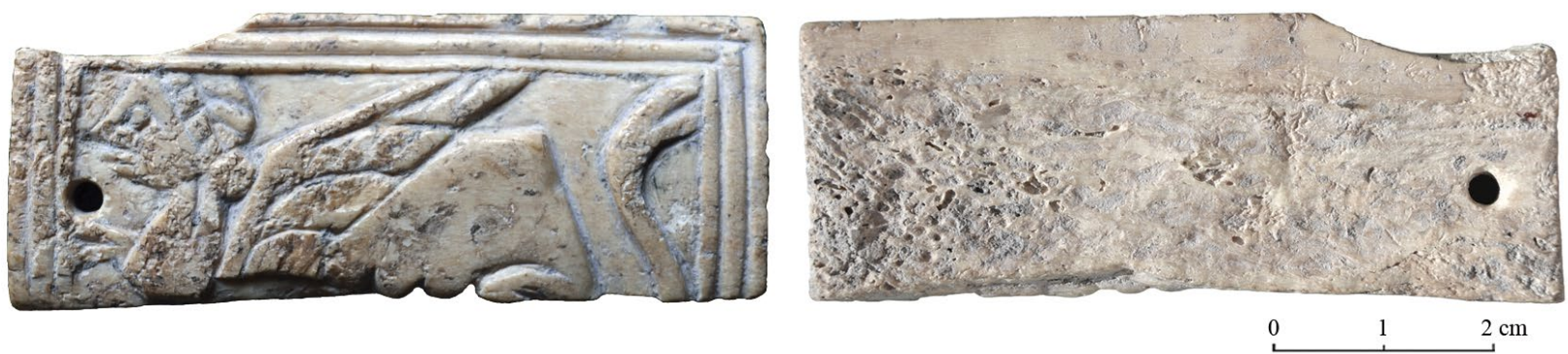

Figura 2: Cara frontal y posterior de la placa con esfinge hallada en Segobriga. Escala 1:1. (Imagen: R. Cebrián)

pero también es posible su relación con su uso posterior como colgante. Por su posición, parece que originalmente este pequeño orificio se situaba en el centro del lado corto de la placa, roto después, de manera que se puede deducir su anchura original, que alcanzó los $3,2 \mathrm{~cm}$

La placa está tallada en un hueso largo de bóvido o caballo, seguramente un húmero o fémur. Su cara dorsal presenta un biselado longitudinal a la pieza en su parte superior, de $0,6 / 0,8 \mathrm{~cm}$ de anchura, que está pulido, y tiene un perfil convexo. El resto de esta cara está sin trabajar. La placa está cortada y sus bordes también están pulidos. Se conserva en buen estado, aunque el lado izquierdo está más erosionado con algunas huellas de roce (Fig. 2).

Muestra en el anverso una esfinge que ocupa todo el espacio. La figura está representada de perfil con el rostro hacia la izquierda. Aparece sentada con las patas delanteras estiradas hacia delante y las traseras flexionadas debajo del cuerpo. El rostro de la esfinge es de mujer y muestra los rasgos muy definidos. El perfil de la cara es redondeado con nariz prominente, de apariencia puntiaguda y línea recta, ligeramente cóncava, que se extiende hasta la frente, y labios muy marcados. Suave barbilla con mentón redondeado y ojo grande y redondo, encuadrado en el rostro por dos suaves líneas incisas que señalan los párpados. El cabello está agrupado en mechones marcados por líneas inclinadas sobre el cráneo en el sentido contrario al de la cinta o diadema, indicada por incisiones oblicuas. La parte superior de la cabeza no está representada al quedarse cortada por el remate externo de la propia placa. El cuello se señala por dos líneas incisas, una horizontal $\mathrm{y}$ otra vertical, en una forma trapezoidal que marca el

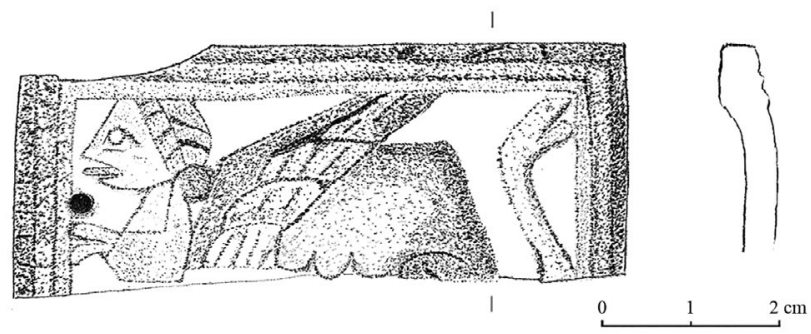

Figura 3: Dibujo de la cara frontal y sección de la placa de hueso procedente de Segobriga. Escala 1:1. (Imagen: R. Cebrián) brazo flexionado. De él sale una de las patas delanteras del felino, señaladas muy esquemáticamente con dos dedos. Y del hombro se alza un motivo circular, que queda bajo la nuca, correspondiente al moño del peinado.

El ala arranca del esternón del animal con un trazado rectilíneo, cambiando de dirección hacia atrás cuando sale del cuerpo mediante un ángulo obtuso. Presenta entonces una profunda línea incisa que la divide en dos longitudinalmente. La representación de la punta del ala de la esfinge se pierde en el marco moldurado. Las plumas de las alas están bien señaladas y divididas en tres filas superpuestas, en cuyo interior finas incisiones en paralelo semejan su detalle. La figura se completa con la talla de los cuartos traseros del animal. En el vientre, tres trazos ovalados delante de las patas posteriores representan las ubres. El contorno de la grupa es rectilíneo y su final es angular. La larga cola separada del cuerpo debe elevarse desde la rabadilla, aunque no se conserva por su estado fragmentario. Su final se curva y se convierte en la cabeza de una serpiente en actitud amenazante, con la boca abierta y marcado ojo (Fig. 3).

El remate exterior de la placa consiste en una triple moldura, de sección semicircular y de grosores desiguales, que constituye el enmarque de la representación figurada. La técnica empleada en la talla de la esfinge es el bajorrelieve. El diseño es sencillo. Anatómicamente la figura está relativamente proporcionada, aunque la manera de tratar el cuerpo del animal es diferente al de la mujer. La ejecución cuidada del ala, las líneas suaves y redondeadas de la cola y abdomen del cuadrúpedo, junto con la ligera sensación de musculatura de su grupa se contrapone al esquematismo del torso femenino.

\section{EL TIPO ICONOGRÁFICO DE LA ESFINGE}

Las facciones del rostro de la esfinge segobrigense muestran la influencia de la plástica griega (Fig. 4: 1). El ojo grande, la nariz triangular y los labios abultados y en línea recta, diseñados con pocos trazos, distinguen las caras de tipo jónico (Croissant, 1977: 355-361). La acentuación de las partes singulares del rostro y el perfil rectilíneo de nariz y frente caracterizan las representaciones griegas arcaizantes y las etruscas llegadas a 


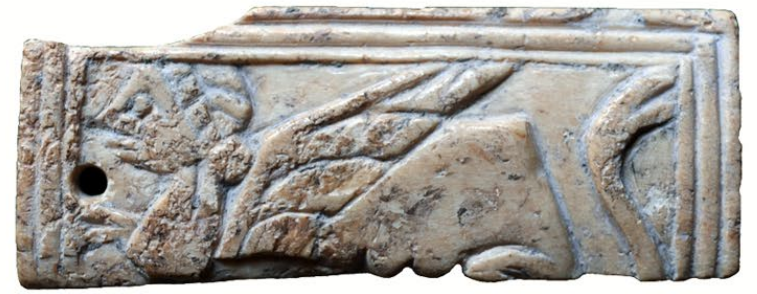

1

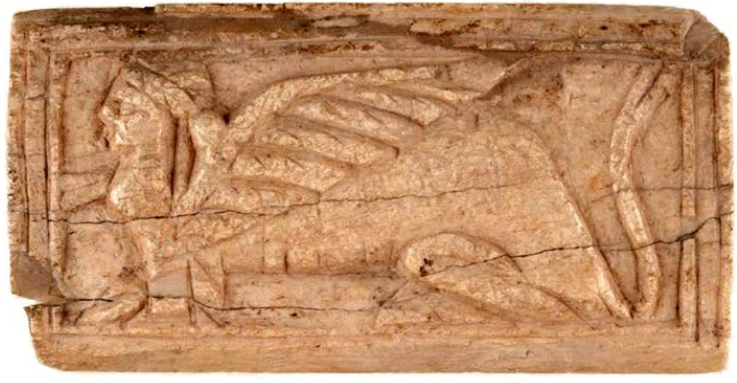

2

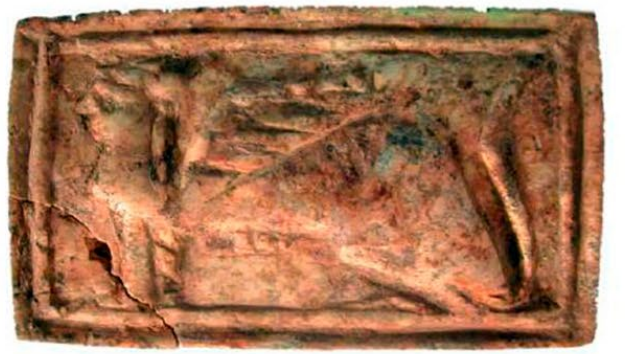

Figura 4: Comparación de las esfinges representadas en las placas de revestimiento de cajas halladas en Segobriga (1), Ibiza (2) y Mérida (3). Escala 1/1. La imagen de la esfinge ibicenca y la emeritense han sido invertidas. Imágenes de R. Cebrián (1), A. Boyero (2) y A. Bejarano (3)

través de los contactos directos con el ámbito jonio. El tratamiento del peinado con el cabello recogido con una diadema alrededor de la cabeza es plenamente griego (Rodrigo y Fortea, 2014). La moda difundida en el siglo $\mathrm{V}$ a. C. se caracterizó en el peinado por llevar el cabello agrupado en un moño bajo. Este tipo de tocado, recogido hacia atrás atándose en un moño a la altura de la nuca del clasicismo griego, seguirá utilizándose hasta las representaciones femeninas de inicios del Imperio (Virgili, 1989: 37).

El mejor paralelo de la pieza procedente de Segobriga se encuentra en una placa de hueso hallada en la necrópolis de Puig des Molins en Ibiza decorada con una esfinge de tipo clásico (Vives, 1917: 84, n. ${ }^{\circ}$ 495, lám. XXVII; Aubet, 1973: 3, tav. XXXIII; Martelli, 1985: 236, fig. 88; Gómez Bellard, 1991: 296) (Fig. 4: 2). A las afinidades estilísticas y formales de ambas piezas se une una tercera procedente de la excavación de una tumba de cremación de la necrópolis situada en la zona de los Jardines del Hipódromo de Mérida (Jiménez Ávila y Barrientos, 2018: 220-221) (Fig. 4: 3).

M. ${ }^{\mathrm{a}}$ E. Aubet identificó la pieza ibicenca como de procedencia etrusca y la atribuyó a la industria ebúrnea de las cajas decoradas con placas en bajorrelieve, destinadas a un consumo femenino de alto nivel social (Martelli, 2000), fechándola a principios del siglo V a. C. La producción de estas cajas se inició a partir del siglo VI a. C. siguiendo modelos orientales, que abandonó a partir de finales de esa centuria en favor de influencias del arte figurativo jonio (Huls, 1957: 162194, pl. XXVII-XXIX). La misma cronología ha sido otorgada al ejemplar emeritense por las similitudes de estilo y forma con la placa de la necrópolis de Puig des Molins (Jiménez Ávila y Barrientos, 2018: 220, fig. 7).
Las características esenciales del diseño del cuerpo de las tres esfinges son iguales. Entre ellas, destaca el tratamiento del abdomen del animal y la cola de serpiente. La determinación del sexo en todas las piezas es clara a partir de la representación de las ubres que cuelgan bajo el vientre del animal. Este hecho es significativo en la búsqueda del modelo iconográfico seguido, que remite el origen al Levante Mediterráneo. En dos placas caladas de marfil procedentes del tesoro del palacio de Meggido (Israel), fechadas entre el 1300 y el 1200 a. C., se representa a sendas esfinges de perfil provistas de mamas y tocadas con modius o tiara cilíndrica (Loud, 1939: 13, pl. 7, 21 y 22) (Fig. 5: 1) y en un ostracon egipcio de $1300 \mathrm{a}$. C. está pintada una esfinge alada femenina, que presenta ubres (Wilkinson, 2003: 139), aunque constituyen una excepción en los ejemplos del Próximo Oriente y están ausentes en Grecia (Caubet, 2000: 14) (Fig. 5: 2). El sexo de la esfinge era determinado por los rasgos masculinos de la cabeza, tales como la barba y el casco, con la singularidad de las denominadas esfinges-toro del Héladico Tardío de Chipre, que muestran los genitales siguiendo los estilos orientales de los centauros (Kourou, 1991:113, pl. XVIII.1), y claramente a partir del siglo V a. C. por la representación de los pechos en el cuerpo humano (Renger, 2013: 33).

En relación a la cola de serpiente de la esfinge, mientras en el ejemplar de Segobriga su cabeza aparece explícitamente diseñada solo se intuye en la pieza ebusitana y no es posible afirmarlo en la placa emeritense. M. ${ }^{\mathrm{a}}$ E. Aubet (1973: 65) llamó la atención sobre lo poco usual de su representación, erecta y terminada en un extremo bífido, aunque puede interpretarse como cabeza de serpiente teniendo en cuenta las similitudes 

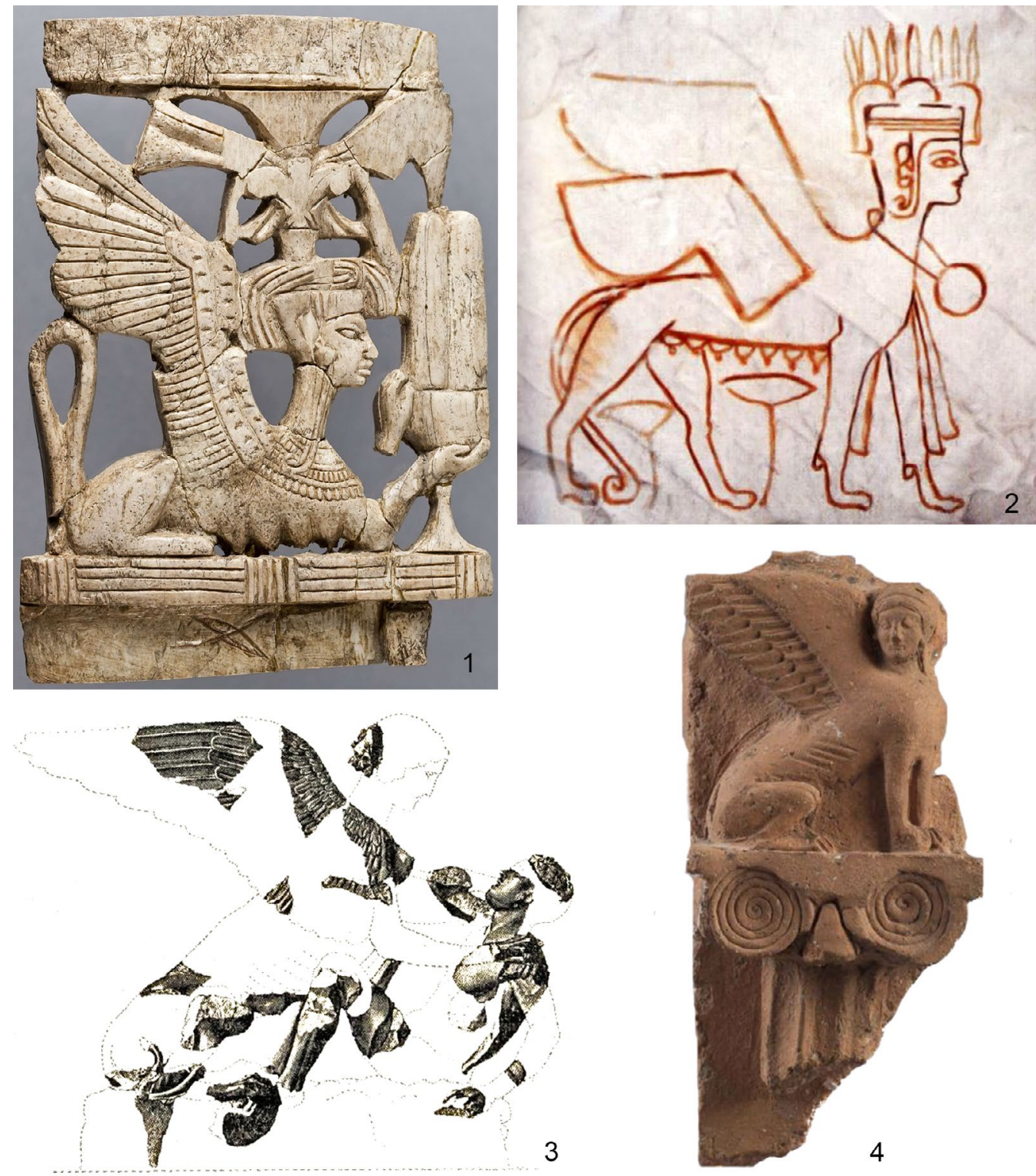

Figura 5: Representaciones de esfinges con ubres en el Mediterráneo. 1. Placa de marfil de Meggido, 1300-1200 a. C. (Department of Art History-University of Chicago). 2. Pintura sobre ostracon egipcio, ca. 1200 a. C. (López Pérez, 2006: 52). 3. Placa de mármol de Éfeso, 500-450 a. C. (Eichler, 1937: 75). 4. Terracota suritálica, 480-460 a. C. (Museum of Fine Arts Boston)

estilísticas con la pieza segobrigense. La influencia del Levante vuelve a estar presente en este aspecto, donde existieron en las representaciones iconográficas del II Milenio a. C. animales atemorizantes como la serpiente, que terminaron por fundirse en figuras híbridas para crear monstruos o demonios (Wiggermann, 19931997: 226). El león, el águila y la serpiente fueron los más comunes, que aparecerán combinados con esfinges y grifos como en el cinturón de bronce de Urartu fechado en el siglo VIII a. C. (Goodnick, 2004: 98-99).

La incorporación al imaginario griego de la esfinge en el ámbito creto-micénico reproducirá una figura con cabeza humana, alas de águila, cuerpo de león o de toro y, en ocasiones, una cola de serpiente (Petit, 2011: 97). A partir del siglo VI a. C. ya había esculturas en piedra de esfinge como protección a los demonios en las estelas funerarias del Ática (Vermeule, 1964: 109).
Una inscripción en el basamento de una estela arcaica hallada en Tesalia otorgaba ese carácter guardián a la esfinge (Richter, 1961: 6). Y el monstruo de la leyenda tebana, siempre femenino, presentará aquel aspecto asociado a la muerte y la destrucción, cuyo mito se representará con frecuencia en los vasos griegos del siglo V a. C. (Hoffmann, 1997: 77-88). Un poco antes, hacia el 540 a. C. dos esfinges aparecerán por primera vez flanqueando la escena principal de Teseo y el Minotauro en una copa ática de figuras negras, donde la leyenda SFISE las identifica con la criatura de Hesíodo. Y en el último tercio de esta centuria se diseñarán ya escenas relacionadas con la esfinge tebana (Krauskopf, 1986: 327-329, fig. 1-4; Tsiafakis, 2003: 81-82, fig. 8).

La expansión de los mitos griegos en el mundo etrusco llegó a través de los contactos comerciales con el Mediterráneo oriental. La esfinge se representó en el 
bestiario de la estatuaria, especialmente, protegiendo la entrada a las necrópolis, como en Vulci o Chiusi (Hus, 1961). De la necrópolis de Caere procede una esfinge de terracota fechada hacia el 630 a. C. con formas orientalizantes, que constituye el ejemplo más antiguo de utilización del animal como protector de la tumba (Rizzo, 2007: 1-9). Y también aparecerá en las cerámicas que imitaron a las corintias, con talleres activos entre el 620 y el 560 a. C. orientadas a la exportación al resto de Italia y al Occidente. En uno de estos talleres se instalará un artesano de la escuela protocorintia, denominado el pintor de la Esfinge Barbuda, que reproducirá el repertorio animalístico de origen greco-oriental con la técnica de las figuras negras (Bandinelli y Torelli, 2000: n. 59 y 60).

Las representaciones de las primeras esfinges etruscas presentan características derivadas de los modelos sirios, en especial, la posición caminante o rampante y, en ocasiones, sentada pero siempre sin atributos genitales, y con las dos alas visibles de diferente apariencia (Smoquina, 2013: 293-297). El carácter fenicio-sirio se reconoce en las esfinges sentadas de los relieves de Chiusi fechados en la primera mitad del siglo VI a. C., donde se presenta de perfil con el ala recta y doble fila de plumas (Jannot,1984: 237).En contraposición, la independencia de los modelos orientales en Grecia fue mayor desde el principio y a partir de mediados del siglo VII a. C. se repetirán figuras de esfinges sentadas o semisentadas con las patas delanteras en posición recta, alas en forma de hoz con terminación redondeada y peinadas con cabello suelto con cinta en la frente o tocada más tarde con polos, y en las que los rasgos faciales indicarán su feminidad en ausencia de claros indicadores sexuales (Sciacca, 2013: 244).

La esfinge femenina, de cuerpo polymaste, alada, con cabeza y busto de mujer con pechos, cuartos traseros y patas de león, aparece representada estrangulando a un joven tebano en Éfeso en la primera mitad del siglo V a. C. (Eichler, 1937: 75), de idéntica composición que la descrita por Pausanias $(\mathrm{V}-11,2)$ en el trono de Zeus en Olimpia (Fig. 5: 3). Del sur de Italia procede un altar de terracota donde se representa a una esfinge con ubres sentada sobre una columna jónica y fechada hacia el 480-460 a. C. (Herrmann, 2003: 282-283, n. ${ }^{\circ}$ 72) (Fig. 5: 4). El tipo iconográfico más repetido en el arte griego a partir del período clásico y durante el helenismo fue la leona alada (Kourou, 2009: 461-462), que presentará, en ocasiones, mamas animales y pechos y brazos femeninos. Siguiendo este modelo, la esfinge se incorporará a Roma, donde la encontramos en el reverso de un cistóforo de Octaviano acuñado en AsiaPérgamo o Éfeso ca. 24-20 a. C. (RIC I $487=$ RPC I 2207) como augurio de una nueva era y en el ámbito funerario decorando los tejados de algunos mausoleos galos de época augustea (Gaggadis-Robin, 2009: 463, add. 16-18).

La introducción de los rasgos anatómicos a los que hemos aludido — representación de las ubres y cola de serpiente- en las tres placas procedentes del extremo occidental del Mediterráneo sugiere, por un lado, la voluntad del artesano de señalar claramente el sexo de la esfinge y no dejarlo a interpretaciones de género
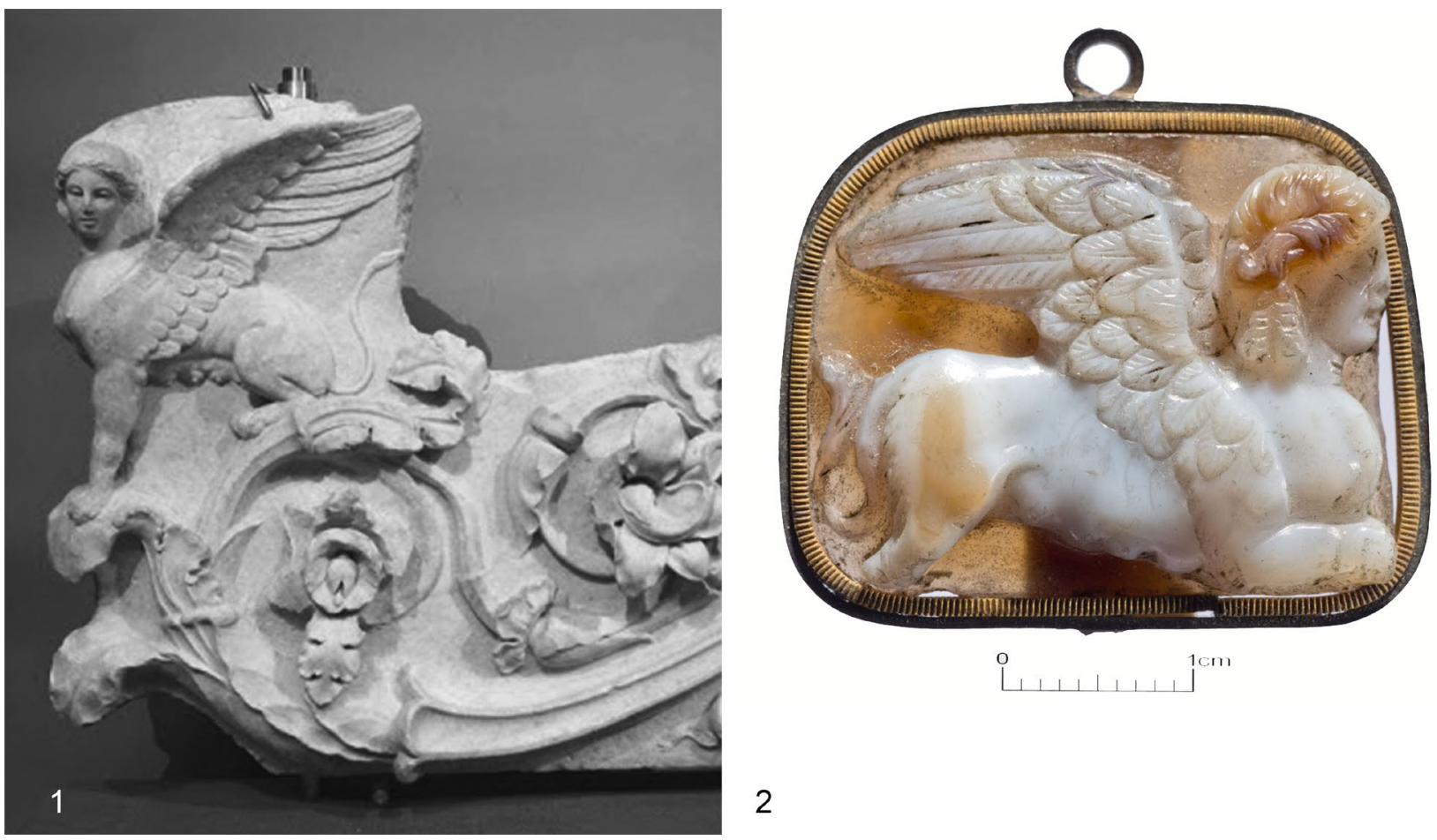

2

Figura 6: Representaciones de esfinge en época augustea. 1. Fragmento del frontón hallado en los denominados jardines de Salustio (Petit, 2020: fig. 5). 2. Camafeo de la colección de la Biblioteca Nacional de Francia (imagen recuperada de: http://medaillesetantiques. bnf.fr/ws/catalogue/app/collection/record/ark:/12148/c33gb1cxhh) 
según el rostro y, por otro, a acentuar su carácter amenazador y temible con la cola de la leona convertida en serpiente. Esa intencionalidad marca una diferencia con la serie de las representaciones animalísticas de carácter meramente decorativas de las placas etruscas fechadas en el primer cuarto del siglo V a. C. (Martelli, 1985: 223-235), que queda definida por la carga iconográfica que transmite el modelo de esfinge, procedente del monstruo helénico de la Tebas de Beocia (Kourou, 2009: 461).

La esfinge formará parte del conjunto de monstra de la mitología griega que se representará en el arte decorativo a partir de época tardorrepublicana desarrollada por talleres neoáticos (Sauron, 1990). Hacia mediados del siglo I a. C., en un frontón de roleos de hojas de acanto de los jardines de Salustio en Roma se talló una esfinge sentada sobre los cuartos traseros, rostro femenino y cuerpo polymaste (Petit, 2020: 245, fig. 5) (Fig. 6: 1). Su imagen, tomada de modelos clásicos, fue reinterpretada por artistas y artesanos romanos, que trataron de resolver - como habían hecho los griegos - el confuso sexo de la esfinge, dotándola de mamas animales - y también humanas - (Herrmann y Van den Hoek, 2005: 279). Acabaría liberada, más tarde, de su protagonismo mitológico para pasar a convertirse en ornato de mobiliario doméstico pues su forma se adaptaba bien a algunos objetos (Daremberg y Saglio, vol. IV.II, $v$. sphinx: 1436). Mientras la elección por parte de Augusto de la esfinge como emblema en su sello personal (Dion Cassio, LI.3.6; Plinio, NH, XXXVII.10) favoreció su difusión en la glíptica. Varios camafeos conservados en la Biblioteca Nacional de Francia reproducen la esfinge griega con rostro femenino, alas de águila y cuerpo de leona con ubres bajo del vientre ${ }^{2}$ (Fig. 6: 2).

\section{EL ESTILO DE LAS PLACAS CON REPRESEN- TACIÓN DE ESFINGE Y SU COMPARACIÓN CON LA PLACA SEGOBRIGENSE}

Las tres placas procedentes de la península ibérica e Ibiza tienen un número elevado de características comunes, formales e iconográficas, lo que a priori consiente agruparlas en un mismo contexto cronológico y cultural, en torno a talleres dedicados a la fabricación de objetos de hueso, entre los que se encontraban estas pequeñas placas de revestimiento de cofres de madera, utilizados para contener perfumes, objetos de tocador $\mathrm{y}$ aseo personal de las mujeres.

Los matices y las variaciones en la representación de las esfinges de las placas de Ibiza y Mérida podrían encontrar una explicación en las limitaciones del trabajo

\footnotetext{
2. LIMC-France LIMCicon ID 16717 (G. Aires, A.-V. Szabados) (http://www.limc-france.fr/objet/16717) y LIMC-France LIMCicon ID 16651 (G. Aires, P. Linant de Bellefonds) (http:// www.limc-france.fr/objet/16651). Consulta: 08-02-2021.
}

de hueso, cuya propia naturaleza impidió el uso de moldes y, por tanto, imposibilitó producir dos objetos iguales (Ayalon, 2005: 5). Si las comparamos, el estilo es tan afín que permitiría aseverar su realización en un mismo taller pues reproducen el mismo tipo iconográfico de esfinge, cuyas diferencias menores solo afectan a su ejecución, suponiendo entonces fuesen productos de artesanos distintos de un mismo taller (Fig. 4: 2 y 3). Sin embargo, los detalles más burdos y escasa destreza técnica de la representación de la esfinge emeritense consienten plantear, como hipótesis, la realización por un artífice local que, en todo caso, tuvo ante sus ojos un modelo original.

Ambas placas son rectangulares, aunque de dimensiones algo distintas. La pieza de Ibiza mide $3,5 \mathrm{~cm}$ de altura y $6,9 \mathrm{~cm}$ de longitud y la de Mérida, $3,2 \mathrm{~cm}$ de altura y $5,5 \mathrm{~cm}$ de longitud. La primera presenta un marco moldurado triple y doble en la segunda, en un trabajo poco cuidado. Idéntica es también la manera de adaptar la figura en el espacio reservado para su diseño, que queda cortada en su parte superior por el enmarque. La única diferencia formal se encuentra en el tratamiento distinto de la cara posterior de las piezas, que puede considerarse otro de los criterios que las aleja del mismo ambiente artesanal. Las placas de marfil o hueso, que decoraron las características kibotia producidas en Etruria, presentan el reverso plano, constituyendo una particularidad del trabajo de los talleres dedicados a su fabricación, y en donde, en ocasiones, se han inciso letras y numerales, que pueden relacionarse con marcas de control de la producción. Este trabajo plano se reconoce en la parte posterior de la placa de Ibiza, mientras el ejemplar de Mérida es ligeramente curvo.

En un contexto estilístico similar se encuentra la placa procedente de Segobriga, aunque ciertos detalles evidencian que se reproduce un modelo distinto del mismo tipo iconográfico de esfinge. El geometrismo del torso humano contrasta con la representación del cuerpo del animal, que conserva rasgos del arcaísmo como la grupa en ángulo recto, más cercana a las imágenes de toros del ámbito creto-micénico, estando ausentes las nuevas tendencias de representación de la anatomía clásica del siglo $\mathrm{V}$ a. $\mathrm{C}$. Y el busto femenino no presenta pechos, que se añadirán desde el siglo $\mathrm{V}$ a. C. en adelante como manera de enfatizar su sexo (Kourou, 2009: 461). El arqueamiento de las alas hacia atrás del cuerpo es rígido en nuestra pieza, presentando la incurvación de las alas de gusto orientalizante, y más redondeada en las de Ibiza y Mérida, sin exhibir ninguna la curvatura del ala griega en el extremo (Aubet, 1973: 65). Sin embargo, el ala arranca en ellas del omóplato del felino como en las de origen griego, pero en la de Segobriga sale del esternón al modo oriental y griego arcaico (Blázquez, 1956: 222) (Fig. 4: 1).

Se aprecian diferencias en el rostro de mujer y peinado. Pelo recogido con una cinta alrededor de la cabeza y moño bajo en el ejemplar hallado en Segobriga y pelo largo con diadema en los de Ibiza y Mérida. Las 
facciones de la cara presentan también diferencias. El perfil de la cara de la esfinge segobrigense está fuertemente acentuado y ejecutado con una línea continua desde el inicio de la frente hasta la nariz puntiaguda, ojo circular, boca abierta y labios fuertemente marcados, en contraposición a la nariz señalada y labios pequeños y bien delineados en las otras dos. El modelo del rostro de la esfinge segobrigense parece derivar del estilo de la cerámica corintia de principios del siglo VI a. C. M. Martelli (1979: 85, fig. 20) insinuó esta influencia para la denominada esfinge del «Melone» de Camucia fechada entre el 580-560 a. C., que evolucionará hacia maneras más griegas a finales de esa centuria y durante la siguiente. También los detalles del rostro diseñados en las placas de marfil y hueso del grupo tarquinense encuadradas cronológicamente en el primer cuarto del siglo V a. C. (Jannot, 1984: 286-287) se asemejan a nuestra pieza.

Quizás el aspecto más helenizante del rostro de la esfinge ibicenca - y emeritense- - así como formas más redondeadas del ala y de la grupa, sea suficiente para situar su ejecución en un momento cronológico inmediatamente posterior a la esfinge segobrigense, quizás en el mismo ambiente artesanal. Al comparar el estilo e iconografía de la esfinge de Ibiza, M. ${ }^{\text {a }}$ E. Aubet (1973: 65) encontró ciertos paralelismos con las representaciones de esfinges en placas de marfil procedentes del santuario de Artemis Orthia en Esparta, aunque se alejaban en el tiempo. Mientras los ejemplares hallados en la capital de Laconia se fechaban entre el siglo VII y la primera mitad del VI a. C. (Boardman, 1963), la cronología de la pieza ibicenca se situaba estilísticamente en el primer cuarto del siglo $\mathrm{V}$ a. C., sugiriendo entonces influencias del ambiente artesanal lacónico-corintio en la industria de kibotia etrusca de época posterior.

Grecia también producirá pequeñas placas rectangulares para decorar cajas o muebles, que están presentes en Micenas, Spata, Delos y en lugares más alejados como Meggido o Egipto (Barnett, 1982: 37). De gran calidad técnica, la esfinge se representará sola, como en cinco placas procedentes de la excavación de algunas tumbas en Spata fechadas en el siglo XII a. C. Sentadas sobre el vientre y alas desplegadas se alejan de los modelos fenicios, y presentan el rostro de perfil $\mathrm{y}$ tocadas con una suerte de mitra (Haussouillier, 1878: pl. XVII.1 y XVIII.1). A. Petit (2011: 121-128) definió los tipos de esfinges griegas que se encuentran en las representaciones figuradas de los siglos VII-VI a. C. entre los que se incluye la esfinge sola, dispuesta en filas o frisos con un carácter aparentemente decorativo, alejándose de las composiciones escénicas del resto de los tipos. Esta representación aislada, en ocasiones, debe relacionarse con el pequeño tamaño de la superficie a decorar como fue el caso de las placas de marfil halladas en algunos santuarios de Esparta o Creta, aunque también se diseñaron solas en vasos cerámicos y formando parte de la arquitectura de los edificios, como en una metopa de Selinunte del siglo VI a. C. Se distinguen en sus imágenes aisladas hasta ocho tipos, incluida la esfinge tebana, por lo que su simple valor decorativo es cuestionado por este autor (Petit, 2011: 130-132).

La artesanía de los marfiles en Etruria llegó desde el Mediterráneo Oriental a principios del siglo VII a. C. junto a sus artesanos, adaptando estilos y motivos -leones, esfinges, grifos, toros, entre otros - con origen en distintas regiones, aunque hubo un matiz que los diferenció de sus vecinos griegos. De uso cultual - estatuillas y pixides - como ofrenda en los santuarios pasó a convertirse en un objeto suntuoso de las clases sociales altas con el que fueron enterradas (Barnett, 1982: 60). A partir del siglo VI a. C. se desarrolló un arte etrusco propio en el trabajo del marfil, aunque muy influenciado por el estilo jonio, que diseñó figuras humanas, de animales y temas mitológicos en pequeñas placas rectangulares para decorar aquellos cofrecitos. También desde finales del siglo VII a. C, un grupo de artesanos etruscos itinerantes estuvieron activos en la zona centro-sur de la península itálica, en el área del Piceno, que produjo pequeños marfiles con temática animalística (Rocco, 1999: 113 y 124). El mismo estilo oriental presenta la decoración de varias urnas cinerarias realizadas en piedra local halladas en la necrópolis de Chiusi y fechadas en la segunda mitad del siglo VI a. C. (Jannot, 1984: 284-288). Con una producción cada vez más orientada al comercio, el siglo V a. C. supuso una gradual sustitución del marfil por el hueso y escasa pericia técnica, que puede seguirse en la esquematización de las figuras representadas (Aubet, 1973-1974: 129; Martelli, 1985: 223). El repertorio animalístico en esta última etapa se caracterizó principalmente por cuadrúpedos —bóvido, león, perro, ciervo y liebre, entre otros-, aves y peces (Martelli, 1985).

Las imágenes de los marfiles etruscos incluyeron la esfinge femenina del tipo helénico arcaico tomada de los modelos protoáticos con el característico peinado con el rizo que cae sobre el cuello o, más tarde, el denominado Etagenperücke o peinado escalonado, englobada en el ciclo orientalizante establecido por Y. Huls (1957: 137-161). Al último cuarto del siglo VI a. C., M. Martelli (1985: 216) asigna las esfinges aladas de origen griego, con cuerpo polymaste y alas en forma de hoz, de una de las necrópolis orvietenses. Dos paneles idénticos, formados de dos piezas, de una caja hallada en una tumba de la necrópolis Crocifisso del Tufo están decorados por dos esfinges aladas tirando de un carro con auriga (Martelli, 1985: 216, figs. 32 b-c), que presentan esta misma apariencia animal al modo griego, pero con ubres de una hembra y también cola de león, mientras los rasgos humanos son masculinos portando un peinado hecho de trenzas, que desciende hasta la altura de los hombros (Fig. 7). Por su parte, el ciclo clásico antiguo desarrollado a lo largo del siglo $\mathrm{V}$ a. C. reprodujo figuras estereotipadas de animales acostados, de cuerpos proporcionados en contraposición al reducido tamaño de las extremidades, y marcada estilización con escasas diferencias entre unos y otros. M. ${ }^{\mathrm{a}}$ E. Aubet encontró semejanzas con 


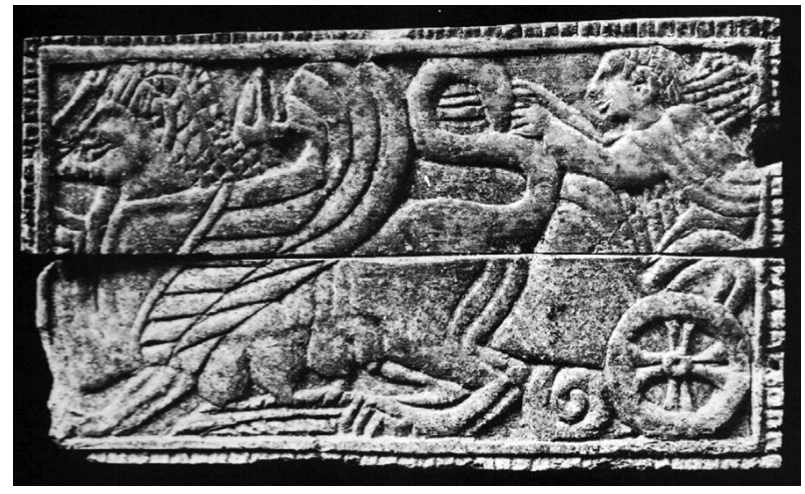

Figura 7: Panel de una caja etrusca con representación de esfinges aladas, ca. 540-500 a. C. (Martelli, 1985: fig. 32b)

una placa conservada en el Antiquarium de Berlín, que fue publicada por L. Pollak (1906: 319, n. ${ }^{\circ}$ XX, fig. 5) y recogida más tarde por Y. Huls (1957: n. $^{\circ} 86$, pl. XLI, 2) y M. Martelli (1985: fig. 53a), donde se reconoce la parte inferior de un animal alado en posición yacente, quizás una esfinge.

Ya hemos aludido a la forma rectangular y plana que presentan las placas ebúrneas decoradas de revestimiento de kibotia etruscas - cofres y píxides-. Sus dimensiones estandarizadas se sitúan entre los 2,3/1,7 $\mathrm{cm}$ de altura y los 10/8,2 $\mathrm{cm}$ de longitud y se definen dos grupos. El primero está formado por dos placas que unidas constituyen el lateral del cofre, donde la figura representada ocupa el espacio de ambas, y un segundo constituido por una placa con la talla de una representación, que junto con otra, forman dos temas superpuestos en una de las caras de la caja (Renard, 1938: 248). Aparecen delimitadas por un marco simple o un friso de ovas y perlas (Martelli, 1985) e incluso hojas (Huls, 1957: 192). En la serie más antigua se disponen figuras que no ocupan todo el campo de la placa rellenándose este con motivos secundarios y en la más moderna ocupan todo el espacio disponible, superando su talla el campo moldurado y, en ocasiones, las cabezas de las figuras quedan cortadas, debido a lo reducido del tamaño de las placas (Jannot, 1984: 285).

El trabajo posterior de la plaquita de Segobriga es diferente al presentar una sección ligeramente curva y contar también con un biselado longitudinal junto al borde de la placa, que no se documenta en la serie de los marfiles etruscos.

En la búsqueda de paralelos para la esfinge segobrigense hemos encontrado cuerpo polymaste en las representaciones talladas sobre marfiles y huesos de la cultura etrusca - placas de Ibiza y Orvieto- y romana. En el Metropolitan Museum of Art de Nueva York se conserva un conjunto de siete placas de revestimiento en marfil ${ }^{3}$, entre las que se encuentra una con la

3. Las placas de revestimiento conservadas en el Metropolitan Museum (https://www.metmuseum.org/) están decoradas con representaciones tomadas de la mitología griega. Tres representación en bajorrelieve de una esfinge femenina, de perfil y en posición sentada, de características tipológico-formales semejante a la de Segobriga. La placa de Nueva York mide 4,7 x 7,1 x 0,5 cm y forma parte de la colección del francés J. Gréau, que fue adquirida por J. Pierpont Morgan en 1913 y llegada al museo como parte de la donación realizada por su hijo en 1917. Las piezas de esta colección fueron ordenadas cronológicamente por la institución, incluyendo las placas en el período romano, aunque el lugar de hallazgo es desconocido, quizás la Gallia teniendo en cuenta la procedencia de la colección (Met, 1917: 33-34). Otra placa de hueso procede de las excavaciones realizadas en la cisterna-ninfeo de la villa Medici en Roma, fechada por el contexto material en época claudio-neroniana (Cardarelli et al., 2005: 152, fig. 6). Mide 4,1 cm de longitud, aunque está medida no es original al encontrarse la pieza fragmentada, y 4,8 cm de anchura. La pieza del Metropolitan Museum presenta pechos humanos y ubres de animal, mientras la otra está desprovista de atributos femeninos y el cuerpo de la leona se diseñó sin mamas. El peinado de la primera presenta cinta y moño bajo y el de la segunda se recoge con una trenza que desde la frente cae por las orejas y termina en un moño, siguiendo los cánones clásicos del período helenístico-romano (Fig. 8).

Con todo, los criterios que permiten atribuir un contexto cultural a la placa de Segobriga son su factura y estilo que, en ningún caso, puede considerarse una imitación de un taller o artesano local. La comparación de la esfinge segobrigense con su paralelo más cercano, la placa de Ibiza, permitiría adscribirla a la serie de marfiles etruscos de época tardoarcaica, uniéndose a los escasísimos ejemplos de este tipo de materiales presentes en la península ibérica (Roldán, 1995-1996). Sin embargo, la esfinge segobrigense tiene un aire distinto, más arcaico, más cercano a la técnica figurativa jonia/oriental, que desde un punto de vista cronológico admite atribuirla al último cuarto del siglo VI a. C. o inicios de la siguiente centuria. En la serie de kibotia etrusca las características tipológico-formales de la placa y el rostro femenino y peinado de nuestra esfinge no encuentra claro acomodo, a pesar de que la composición y temática sea similar, por lo que no es descartable una filiación cultural griega.

de ellas presentan a Eros caminando hacia la izquierda, una de ellas con un canasto de frutas en la parte inferior (n. ${ }^{\circ}$ inv. Met: 17.190.95, 17.190.96 y 17.190.97), otra a Heracles (n. ${ }^{\circ}$ inv. Met: 17.190.99) y una tercera a Ménade (n. ${ }^{\circ}$ inv. Met: 17.190.100). Un cesto con frutas decora otra de las placas (n. ${ }^{\circ}$ inv. Met: 17.190.98) y la última tiene tallada en bajorrelieve una esfinge (n. ${ }^{\circ}$ inv. Met: 17.190.99). Todas las placas son rectangulares, algunas en posición vertical -de 14,4/10,5 cm de altura — y otras en horizontal — de 4,8/4,7 cm de altura-, sin que se pueda determinar si formaron parte de una o varias cajas de madera. A pesar de ello, las dos figuras de Eros caminando a izquierda son idénticas y presentan dimensiones similares por lo que no es descartable que perteneciesen al mismo cofre. Consulta: 08-03-2021. 

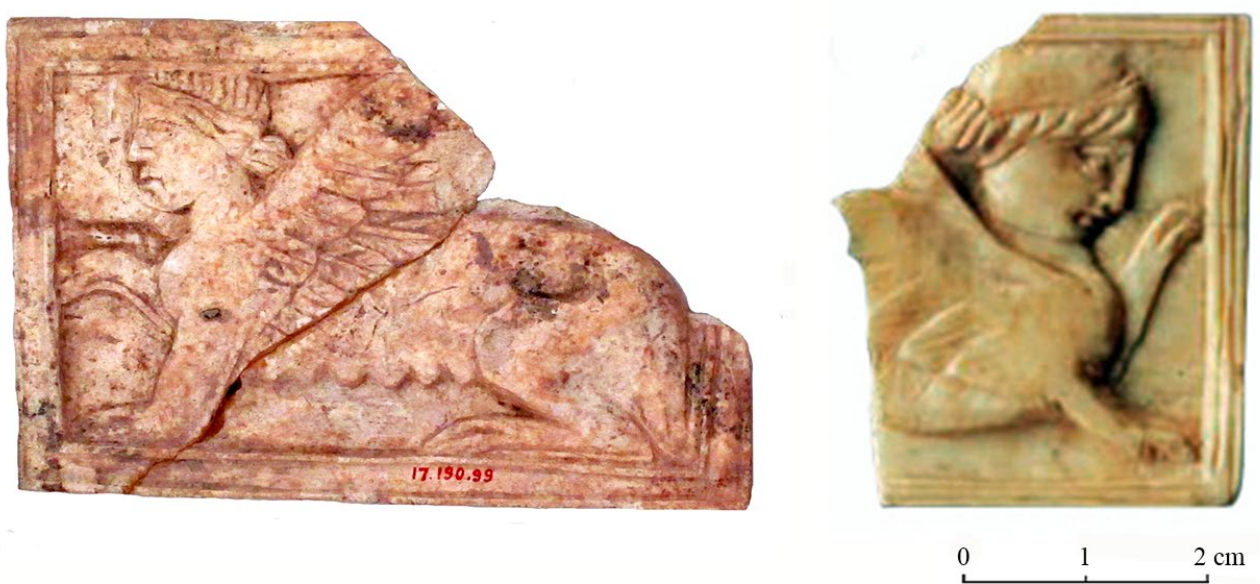

Figura 8: Placas de revestimiento de cofres con representación de esfinge procedentes del Metropolitan Museum of Art de Nueva York (izquierda) y de la villa Medici en Roma (derecha). Escala 1/1. Imagen recuperada de https://www.metmuseum.org/art/collection/ search/249195 y Cardarelli et al., 2015: fig. 6, respectivamente

\section{LA DIFUSIÓN DE KIBOTIA EN LA PENÍN- SULA IBÉRICA E IBIZA Y EL CONTEXTO ARQUEOLÓGICO DE LA ESFINGE DE SEGO- BRIGA}

La distribución geográfica de objetos etruscos en el extremo occidental del Mediterráneo se circunscribe al área balear, Levante peninsular, Andalucía y la Meseta (Botto y Vives-Ferrándiz, 2006). Pequeñas placas de marfil o hueso pertenecientes a la decoración de cajas se han hallado hasta el momento en contextos funerarios. La relación que parece revelar el hallazgo seguro de estas cajas en el ámbito funerario consiente pensar en el aspecto simbólico que alcanzaron. Su presencia limitada solo a algunas sepulturas, ricas en ajuares, es indicativa de su vinculación a determinados grupos sociales, en exclusiva a miembros de la elite local indígena que adquirieron en vida productos suntuarios procedentes del Mediterráneo.

Un conjunto significativo se ha hallado en áreas cementeriales de la provincia de Albacete, concretamente, en las necrópolis de Los Villares en Hoya Gonzalo y en la de Hoya de Santa Ana, cuya ocupación se sitúa entre finales del siglo VI a. C. y el siglo II d. C. (Blánquez, 1987: 27). De esta última proceden tres placas rectangulares con motivos geométricos, similares a la documentada en una de las tumbas de la necrópolis Martí de Ampurias, para las que se ha propuesto un ambiente artesanal local (Roldán, 19951996: 18), que imitó la artesanía de kibotia y, por tanto, su origen foráneo debe quedar descartado. En la primera se localizaron tres placas de marfil decoradas con una escena de banquete, escena de silenos y ánades en procesión pertenecientes a dos cajas (Roldán, 19951996: 11-15, figs. 5 a 9), que formaron parte del ajuar de la tumba 20, encuadrable en la fase II del cementerio fechada en el siglo $\mathrm{V}$ a. $\mathrm{C}$. Y un segundo grupo formado por 12 fragmentos de placas procede de la tumba 25 con la misma cronología, entre las que se reconocen ejemplares lisos, elementos geométricos y una escena con dos felinos afrontados (Blánquez, 1990: nota 3, figs. 64-66; 1991: 328). Finalmente, en el fondo arqueológico Ricardo Marsal Monzón se conservan numerosas placas halladas en la excavación de varias tumbas de la necrópolis de la Carada (Espeluy, Jaén), que decoraron, al menos, dos cajas de madera. Una de ellas (ref. conjunto B24-001) presenta cuatro pies de esquina en forma de garras y estuvo decorada por placas de marfil, unas lisas delimitadas por molduras y otras con animales (Rísquez y Molinos, 2014: 147 y fig. 1), entre las que se encuentra un animal agazapado a izquierda enmarcado por un listel y un ave, que se ajustan a las características estilísticas de las representaciones de la artesanía etrusca datable en el primer cuarto del siglo V a. C., con paralelos en Chiusi, Delos y Atenas (Martelli, 1990).

Se ha apuntado un origen etrusco (Gran-Aymerich y Gran-Aymerich, 2002: 213 y fig. 30) para dos placas de marfil encontradas en el túmulo de El Turuñuelo (Mérida, Badajoz), aunque una de ellas, en relieve, con representación de un personaje barbado sujetando una maza con uno de los brazos, quizás un centauro, también se ha atribuido a un taller griego arcaico (Jiménez Ávila y Ortega, 2006: 115 y fig. 3). Y la otra, no presenta decoración salvo una fina línea incisa junto al borde, lo que dificulta su atribución a un ámbito productivo concreto (Botto y Vives-Ferrándiz, 2006: 130-131). El contexto cronológico proporcionado por los materiales a las que se asocian permite datarlas a finales del siglo V a. C. (Jiménez Ávila y Domínguez de la Concha, 1995: 145). De confirmarse el origen griego de la primera de estas placas, constituiría la única evidencia, por el momento, en la península ibérica de kibotia helena

En la lista de placas etruscas la primera en incluirse fue la esfinge de Ibiza recuperada por A. Vives y Escudero de las excavaciones, que el mismo financió entre los años 1910 y 1914, en la necrópolis de Puig des Molins de Ibiza. La colección de piezas de 
cronología púnica y romana halladas en estas excavaciones la publicaría uno años más tarde (Vives, 1917) pero sin datos sobre el contexto arqueológico. De la necrópolis procede también una pieza de marfil, de $5 \mathrm{~cm}$ de longitud, con representación de una Victoria alada, que A. Vives (1917: 80, n. ${ }^{\circ}$ 443, lám. XXXI.1) consideró correspondía al pie de algún cofre y M. ${ }^{\mathrm{a}} \mathrm{E}$. Aubet (1973: 59, nota 1) fechó en época romana. Y una segunda pieza de marfil con cabeza de Sileno fue atribuida por aquel (Vives, 1917: 80, n. ${ }^{\circ} 444$ y lám. XXXI.2) a una placa de revestimiento de algún mango por su forma arqueada y perforación circular para su fijación con un remache y adscribió al mundo griego helenístico. La pieza encuentra sus paralelos en los fulcra ebúrneos que decoraron lechos funerario de origen helenístico. Un ejemplar idéntico se encuentra en un aplique de Sileno de un fulcrum procedente de las excavaciones en el ágora de Atenas fechado hacia el siglo II a. C. (Doumeyrou, 1989: 10 y fig. 7). Otros elementos de bronce, como asas, remaches con cadenas, anillas y clavos, aseguran también el hallazgo en la necrópolis de capsae de época romana (Vives, 1917: 59-60, n. ${ }^{\circ}$ 239-241, 243-247, lám. XVI.13-17, lám. XVII.1-8 y 10).

El contexto de hallazgo de la placa con esfinge emeritense es también funerario. La pieza se recuperó en la excavación de una tumba de cremación del espacio funerario identificado en el área de los Jardines del Hipódromo y fechada en el siglo I d. C. (Jiménez Ávila y Barrientos, 2018: 220). Las obras de instalación de un colector en 2004 motivaron la intervención arqueológica en una zona cercana al circo de la ciudad, documentándose algunas sepulturas de una necrópolis altoimperial, utilizada entre mediados del siglo I d. C. y la primera mitad de la centuria siguiente. En el interior de la tumba de bustum A 52 del sector 6 se recuperó un ajuar formado por la placa de hueso con esfinge, un huso y una moneda de bronce (Bejarano, 2007: 146 y fig. 16), a los que debe añadirse un anillo de bronce, un posible stylus, una lucerna tipo Deneauve Va, un vaso de cerámica común imitación de la forma Mayet XLIII de paredes finas y un ungüentario tubular de vidrio.

La pieza de Segobriga se encontró en un contexto secundario en el interior del espacio urbano, cuando la pieza ya no formaba parte de la decoración de una caja. La cronología aportada por los materiales cerámicos recuperados del estrato en el que se halló la placa se sitúa en época tardorromana. Aunque está presente un fragmento de plato de barniz negro - campaniense C - fechada en el siglo I a. C., que debe considerarse residual, la datación del nivel arqueológico se establece a partir de la presencia de ollas características de los siglos IV y V d. C. También se encuentra un cuenco con pitorro de cerámica común, forma Vegas tipos 11.3, fechado en época bajoimperial. Sin embargo, el conjunto más numeroso de cerámicas corresponde al último tercio del siglo I d. C. entre las que destaca un cuenco de las primeras producciones de terra sigillata hispánica, forma Drag. 29b, un bol de terra sigillata gálica marmorata, forma Ritterling 5c, que acompañan a cerámicas comunes — jarras, paropsis, cuencos, lebes y urnas, principalmente - y pintadas de tradición celtibérica, representativas del repertorio formal del siglo I d. C. También se documentan algunas formas de cerámica de cocina de la misma cronología, como ollas de borde cuadrangular, una cazuela de borde reentrante, un asa de una jarra y un perfil completo de una tapadera de botón. El material anfórico se reduce a un pivote de ánfora vinaria de origen rodio y a otro pivote de una Dressel 9, de salazones de la Bética. Junto a estos materiales, se encontró una cazoleta de hueso, prácticamente completa, circular y cóncava, de 2,6 cm de diámetro, que corresponde a una cucharilla del tipo Beal A XXV 1, de uso cosmético o médico, de cronología altoimperial.

Su identificación, a partir de sus características formales, como placa del revestimiento decorativo de una caja de madera para guardar objetos de aseo personal femenino (Daremberg y Saglio, vol. I, v. arca: 362-364) obliga a considerar que en el contexto en el que se halló era un simple elemento aislado pues no se documentó el resto de placas y elementos decorativos de la caja original. Ello no significa obligatoriamente que la pieza fuese atesorada durante siglos pues, si la cronología que proponemos para la pieza es correcta, significaría que la caja — y después la pieza — se guardó durante más de diez siglos. Existe otra explicación más razonable y es que alguien encontró la placa casualmente y la guardó, y quizás la utilizó como colgante, lo que explicaría el orificio que presenta la pieza sobre el marco moldurado, aunque no es posible determinar el espacio temporal en el que la pieza mantuvo este uso. La misma explicación es válida para la placa con esfinge emeritense hallada en un contexto funerario altoimperial sin evidencias de que formase parte ya de una caja pero, sin duda, debió tratarse de un objeto muy apreciado por la difunta como para enterrarse con ella.

\section{CONCLUSIONES}

Las evidencias más antiguas del comercio de productos importados desde el Mediterráneo en Segobriga corresponden a finales del siglo VI a. C. y la primera mitad de la siguiente centuria, aunque se trata de un número limitado de piezas. La placa con esfinge puede incorporarse a la lista de estos objetos que han sido hallados en las excavaciones arqueológicas del espacio urbano, entre los que se encuentra un fragmento de cerámica de figuras rojas y un colgante de cornalina y oro, de origen púnico. El vaso de Nola fechado a mediados del siglo $\mathrm{V}$ a. C. fue documentado en la excavación de 1983 en el área sacra situada al sur de la plaza tiberiana (Almagro-Gorbea y Lorrio, 1989: 200, fig. 88) y, por tanto, corresponde a un hallazgo muy cercano a la placa. Por otra parte, el colgante fálico fue encontrado 


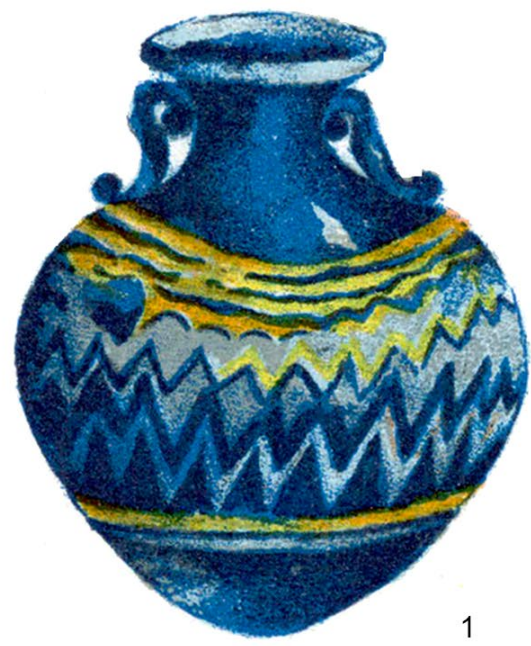

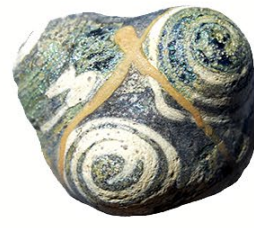

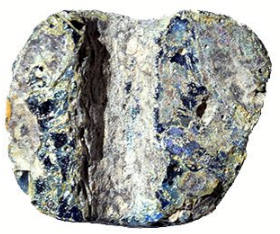

2

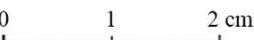

Figura 9: 1. Acuarela realizada por P. Quintero (1913: 84) del aryballos de vidrio polícromo hallado en «una tierra de labor al Oriente de Cabeza del Griego». 2. Cuenta de collar esférica, de tipo oculada, realizada en vidrio procedente de niveles superficiales del área de excavación donde se halló la placa con esfinge

en un vertedero asociado a la construcción del anfiteatro de época vespasianea y se fecha hacia el siglo VI a. C por sus paralelos en Tharros y Cartago (AlmagroGorbea y Lorrio, 2006-2007: 156, fig. 3.2).

Un caso aparte lo constituyen los materiales de origen griego y etrusco conocidos por las excavaciones de R. García Soria y P. Quintero en Segobriga y en Uclés pues su procedencia segura del cerro de Cabeza de Griego no está clara (Lorrio y Sánchez de Prado, 2002). Se trata de un jarro de bronce u olpe (Lorrio, 2007: 255, figs. 2.1 y 5.1), producido en los talleres de Vulci o de la Etruria septentrional, cuya cronología se sitúa $c a .600$ a. C. (Bardelli y Graells, 2012: 34) y un aryballos de vidrio polícromo del ámbito griego (Feugère, 1989: 44; Lorrio, 2007: 265, fig. 5.17) fabricado entre finales del VI y el siglo V a. C. ${ }^{4}$ (Fig. 9: 1). El hallazgo del olpe etrusco en la necrópolis de Haza del Arca de Uclés parece estar claro pero creemos que nada impide pensar que el aryballos se encontró en Segobriga. Las razones se encuentran en la tipología de la sepultura donde apareció el ungüentario de vidrio, descrita por P. Quintero y conocida en la ciudad en un sector de la necrópolis septentrional, aunque sin presencia de thecae plumbae (Almagro Basch, 1979), en la ausencia de excavaciones al oriente del cerro donde aquel señala que se encontró y, por tanto, sin constatación arqueológica de la existencia o no de áreas cementeriales y su adscripción cronológica y, por último, en los hallazgos puntuales en las excavaciones en la ciudad de diversos materiales importados concordantes con su cronología. Si esto fuese así, no sería

4. El aryballos de vidrio modelado sobre núcleo de arena segobrigense se incluye en el denominado «Mediterranean Group I» de D. B. Harden (1981). descartable que la placa con esfinge procediese originariamente de esta necrópolis, tomando en consideración el contexto de hallazgo de los otros ejemplares de la península ibérica e Ibiza.

Recientemente, hemos localizado en los almacenes del Museo de Cuenca (caja R-259 C) una cuenta de collar, de forma esférica (inv. AA85/8/7), fabricada en pasta de vidrio polícroma, con decoración oculada, que fue hallada en superficie en 1985 en la zona del yacimiento de donde procede la placa con esfinge. La localización de los talleres que produjeron este tipo de adorno personal sigue en discusión por la investigación, aunque se admite una zona de fabricación en los ambientes púnicos del Mediterráneo central occidental (Grose, 1989: 109) a partir de finales del siglo VI a. C. (Fig. 9: 2). El área de dispersión de estas cuentas en la península ibérica e islas baleares es amplia (Ruano Ruiz, 1996: 46-56, mapa $\mathrm{n}^{\circ} .3$ ), siendo más frecuentes en la costa mediterránea pero también se han hallado en áreas interiores, como en la cercana necrópolis de Las Madrigueras en Carrascosa del Campo, cuya cronología no es anterior al siglo IV a. C. (Almagro-Gorbea, 1965: 98).

La pieza de Segobriga complementa el mapa de distribución de las importaciones de kibotia - etrusca o griega - en el extremo occidental del Mediterráneo a partir de finales del siglo VI e inicios del V a. C. $\mathrm{Su}$ presencia en el castro prerromano asegura la llegada de productos de lujo destinados a una aristocracia local. Su importante papel en el cruce de las principales vías de comunicación, debido a su estratégico emplazamiento, y el control de la ruta de trashumancia (Almagro-Gorbea y Lorrio, 2006-2007:151) permitió las relaciones comerciales con el entorno mediterráneo desde la costa meridional andaluza y el levante peninsular. 


\section{AGRADECIMIENTOS}

A José Yravedra y a Isabel Rodríguez López, de la Universidad Complutense de Madrid, respectivamente, por la identificación del material óseo sobre el que se talló la pieza segobrigense y los comentarios acerca del estilo de la placa de hueso de Segobriga. A Ana María Bejarano, arqueóloga del Consorcio Ciudad Monumental Histórica-Artística y Arqueológica de Mérida, por la información sobre la sepultura en la que apareció una plaquita con esfinge, así como la remisión de las fotografías de la pieza.

\section{REFERENCIAS}

Abascal, J. M., Alberola, A., Cebrián, R. y Hortelano, I (2010). Segobriga 2009. Resumen de las intervenciones arqueológicas. Cuenca: Consorcio del Parque Arqueológico de Segobriga.

Almagro Basch, M. (1979). Necrópolis romana de las parcelas números 45 y 46 de Segobriga (Saelices, Cuenca). Noticiario Arqueológico Hispánico, 7, 211-246.

Almagro Basch, M. (1983). Saelices. Segobriga. En Memoria de las actuaciones programadas en el año 1982. Recuperado de: https://prensahistorica.mcu.es/es/consulta/registro. do? id $=11000498877$

Almagro-Gorbea, M. (1965): La necrópolis celtibérica de Las Madrigueras, Carrascosa del Campo (Cuenca). Excavaciones Arqueológicas en España, 41. Madrid: Ministerio de Educación Nacional.

Almagro-Gorbea, M. y Abascal, J. M. (2008). Termes y Segobriga y los orígenes del culto imperial en Hispania. En E. La Rocca, P. León y C. Parisi (Eds.). Le due patrie acquisite.Studi di archeologia dedicati a Walter Trillmich (pp. 15-25). Bullettino della Commissione Archeologica Comunale di Roma. Supplementi, 18. Roma: L'Erma di Bretschneider.

Almagro-Gorbea, M. y Lorrio, A. (1989). Segobriga III. La muralla norte y la puerta principal: campañas 1986-1987. Cuenca: Diputación Provincial de Cuenca.

Almagro-Gorbea, M. y Lorrio, A. (2006-2007). De Sego a Augusto: los orígenes celtibéricos de Segobriga. Boletín del Seminario de Estudios de Arte y Arqueología: Arqueología, LXXII-LXXIII, 143-181. Recuperado de: http://uvadoc.uva. es/handle/10324/9157

Ayalon, E. (2005). The assemblage of bone and ivory artefacts from Caesarea Maritima, Israel.1st-13th centuries CE. BAR International Series, 1457. Oxford: Archaeopress. DOI: https://doi.org/10.30861/9781841718958

Aubet, M. ${ }^{\text {a }}$ E. (1973).Dos marfiles con representación de esfinge de la necrópolis púnica de Ibiza. Rivista di Studi Fenici, 1(1), 59-68.

Aubet, M. ${ }^{a}$ E. (1973-1974). El origen de las placas en hueso de Nora. Studi Sardi, XXIII(1), 125-130.
Bandinelli, R. y Torelli, M. (2000). El arte de la Antigüedad Clásica. Etruria-Roma. Madrid: Akal.

Bardelli, G. y Graells, R. (2012). Wein, Weib und Gesang. A propósito de tres apliques de bronce arcaicos entre la Península Ibérica y Baleares. Archivo Español de Arqueología, 85, 23-42. DOI: https://doi.org/10.3989/aespa.085.012.002

Barner, R. D. (1982). Ancient ivories in the Middle. Recuperado de: http://www.jstor.org/stable/43587583

Bejarano, A. M. ${ }^{\text {a }}$ (2007). Un espacio funerario generado en el entorno del circo romano de Augusta Emerita. Intervención arqueológica realizada en un área situada en los Jardines del Hipódromo s/n. Mérida. Excavaciones Arqueológicas, 10, 131-151.

Blánquez, J. (1987). Notas acerca de una revisión de la necrópolis ibérica de la Hoya de Santa Ana (Chinchilla, Albacete). Cuadernos de Prehistoria y Arqueología de la Universidad Autonóma de Madrid, 13-14, 9-28. DOI: https:// doi.org/10.15366/cupauam1987.14.002

Blánquez, J. (1990). La formación del mundo Ibérico en el sureste de la Meseta ((estudio arqueológico de las necrópolis ibéricas de la provincia de Albacete). Albacete: Instituto de Estudios Albacetenses.

Blánquez, J. (1991). El impacto del mundo griego en los pueblos ibéricos de la Meseta. Huelva Arqueológica, XIII(1), 321-354.

Blázquez, J. M. ' . (1956). Pinax fenicio con esfinge y árbol sagrado. Zephyrus, 7, 217-228. Recuperado de: https://revistas.usal.es/index.php/0514-7336/article/view/3716/3733

Botto, M. y Vives-Ferrándiz, J. (2006). Importazioni etrusche tra le Baleari e la Penisola Iberica (VIII - prima metà del V sec. A.C.). En G. M. della Fina (Ed.). Gli Etruschi e il Mediterraneo. Commerci e politica (pp. 117-196). Orvieto: Quasar.

Boardman, J. (1963). Artemis Orthia and Chronology. Annual of the British School at Athens, 58, 1-7. DOI: https://doi. org/10.1017/S0068245400013721

Brümmer, E. (1985). Griechische Truhenbehälter. Jahrbuch de Deutschen Archäologischen Instituts, 100, 1-168.

Cardarelli, V., Castelli, G., Falzone, S., Fratini, G., Montali, I. y Moriconi, F. (2005). Villa Medici, lo scavo degli iterri dietro la falegnameria di villa Medici. Il contesto dei materiali. Bollettino di Archeologia On line, VI, 147168. Recuperado de: https://bollettinodiarcheologiaonline. beniculturali.it/wp-content/uploads/2018/12/2015 2-3-4 Cardarelli-et-al 28dic-.pdf

Caubet, A. (2000). Deux sphinx d'ivoire au musée du Louvre. Monuments et mémoires de la Fondation Eugène Piot, 79, 5-29. DOI: https://doi.org/10.3406/piot.2000.1371

Cebrián, R. (2021). Segobriga, civitas stipendiaria (Plin. HN 3.25). Nuevos datos arqueológicos sobre el urbanismo inicial de la ciudad. Gerión, 35(2), 471-489. DOI: https://doi. org/10.5209/GERI.59920

Cebrián, R. (2021) Formas, organización y representación del culto imperial en Segobriga. En G. Carrasco (Coord.). 
Cultos y religión romana en Castilla-La Mancha (pp. 301329). Cuenca: Universidad de Castilla-La Mancha.

Croissant, F. (1977). Sur quelques visages ioniens de la fin de l'archaïsme. Bulletin de correspondance hellénique, 4, 337-363. DOI: https://doi.org/10.3406/bch.1977.5130

Daremberg, Ch. y Saglio, E. (1877-1919). Dictionaire des Antiquités Grecques et Romaines. Paris: Hachette.

Doumeyrou, E. (1989). An Ivory Fulcrum Medallion. The J. Paul Getty Museum Journal, 17, 5-14. Recuperado de: https://www.jstor.org/stable/i394548

Eichler, F. (1937). Thebanische Sphinx. Ein Bildwerk aus Ephesos. Jahreshefte des Österreichischen Archäologischen, $30,75-110$

Feugère, M. (1989). Les vases en verre sur noyau d'argile en Méditerranée nord-occidentales. En M. Feugère (Dir.). Le verre préromain en Europe occidentale (pp. 29-62). Montagnac: Editions Monique Mergoil.

Gaggadis-Robin, V. (2009). Le sphinx dans le monde romain. En N. Kourou, I. Krauskopf y S. E. Kataskis (Reds.). v. Sphinx. Lexicon Iconographicum Mitologiae Classicae (LRMC) Suppl. (p. 463). Düsseldorf: Artemis

Gómez Bellard, C. (1991). Kantharos, aryballos y esfinge de hueso: reflexiones a partir de los materiales etruscos en Ibiza. En J. Remesal y O. Musso (Coords.). La presencia del material etrusco en el ámbito de la colonización arcaica en la Península Ibérica (pp. 295-308). Barcelona: Universitat de Barcelona.

Goodnick, J. (2004). Dragons, Monsters and Fabulous Beasts. Jerusalem: Bible Lands Museum.

Gran-Aymerich, J. y Gran-Aymerich, É. (2002). Les Étrusques en Gaule et en Ibérie: Du mythe à la Réalité des Dernières Dècouvertes. Etruscan Studies: Journal of the Etruscan Foundation, 9, 207-226. Recuperado de: https:// scholarworks.umass.edu/etruscan studies/vo19/iss1/17

Grose, D. F. (1989). Early Ancient Glass. Core formed, rodformed and cast vessels and objects from the late Bronze Age to the Early Roman Empire, 1600 B.C. to A.D. 50. New York: The Toledo Museum of Art.

Harden, D. B. (1981). Catalogue of Greek and Roman Glass in the British Museum. London: British Museum.

Haussouillier, B. (1878). Catalogue descriptif des objets découverts á Spata. Bulletin de correspondance hellénique, 2, 185-228. DOI: https://doi.org/10.3406/bch.1878.4451

Herrmann, J. (2003): Catalogue of the exhibition. Egyptian and Near Eastern Mischwesen. En J. M. Padgett, W. A. P. Childs y D S Tsiaphakē (Eds.). The Centaur's Smile: The Human Animal in Early Greek Art. Princeton: Princeton University Art Museum.

Herrmann, J. y Van den Hoek, A. (2005). The sphinx: sculptures as a theological symbol in Plutarch and Clement of Alexandria. En A. Hilhorst y G. H. Van Kooten (Eds.). The Wisdom of Egypt (pp. 285-310). DOI: https://doi. org/10.1163/9789004331013 017
Hoffmann, H. (1997). Sotades. Symbols of Immortality on Greek Vases. Oxford: Clarendon Press.

Huls, Y. (1957). Ivoires d'Étrurie. Bruxelles: Palais des Académies.

Hus, A. (1961). Recherches sur la statuaire en pierre étrusque archaïque. Bibliotèque des Écoles françaises d'Athènes et de Rome, 198. Paris: E. de Boccard.

Jannot, J.-R. (1984). Les reliefs archaïques de Chiusi. École Française de Rome, 71. Rome: École Française de Rome.

Jiménez Ávila, J. y Barrientos, T. (2018). Mérida y su territorio antes de Augusta Emerita: antecedentes, realidad arqueológica y proyección social. En J. C. López Díaz, J. Jiménez Ávila y F. Palma (Eds.). Historia de Mérida. Tomo I. De los antecedentes de Augusta Emerita al fin del medievo (pp. 209-268). Badajoz: Consorcio de la Ciudad Monumental Histórico-Artística y Arqueológica de Mérida.

Jiménez Ávila, J. y Domínguez de la Concha. C. (1995). Materiales protohistóricos de El Turuñuelo (Mérida, Badajoz). Pyrenae, 26, 131-151.

Jiménez Ávila, J. y Ortega, J. (2006). El comercio griego en Extremadura (ss. VI-IV a. C.). Revista de estudios extremeños, 62(1), 105-140.

Kourou, N. (1991). Aegean Orientalizing versus Oriental Art: the evidence of monsters. En V. Karageorghis (Ed.). The civilizations of the Aegean and their diffusion in Cypurs and the Eastern Mediterranean, 2000-600 B.C. Proceedings of the International Symposium (Larnaca, 1989) (pp. 110-123). Larnaca, Cyprus: Pierides Foundation.

Kourou, N. (2009). The sphinx in Greece. En N. Kourou, I. Krauskopf y S. E. Kataskis (Reds.). v. Sphinx. Lexicon Iconographicum Mitologiae Classicae (LRMC) Suppl. (pp. 458-463). Düsseldorf: Artemis.

Krauskopf, I. (1986). Edipo nell'Arte Antica. En B. Gentili y R. Pretagostini (Eds.). Edipo. Il teatro greco e la cultura europea. Atti del Convegno Internazionale (Urbino, 1982) (pp. 327-341). Pesaro - Urbino: Edizioni dell'Ateneo.

López Pérez, A (2006). El gran enigma de la esfinge. Revista de Arqueología, 297, 48-57.

Lorrio, A. (2007). Historiografía y nuevas interpretaciones: la necrópolis de la Edad del Hierro de Haza del Arca (Uclés, Cuenca). Caesaraugusta, 78, 251-278. Recuperado de: https://ifc.dpz.es/recursos/publicaciones/27/22/18.lorrio.pdf

Lorrio, A. (2012). Procesos de continuidad y discontinuidad entre los oppida celtibéricos y las ciudades romanas en la Meseta Sur: los casos de Segobriga y Ercavica. En G. Carrasco (Coord.). La ciudad romana en Castilla-La Mancha (pp. 225-285). Cuenca: Universidad de Castilla-La Mancha.

Lorrio, A. y Sánchez de Prado, M. ${ }^{\mathrm{a}}$ D. (2002). La necrópolis romana de Haza del Arca y el santuario del Deus Airoinis en la Fuente Redonda (Uclés, Cuenca). Iberia: Revista de la Antigüedad, 5, 161-194. Recuperado de: https://publicaciones.unirioja.es/ojs/index.php/iberia/article/view/277

Loud, G. (1939). The Meggiddo ivories. Oriental Institute Publications, LII. Chicago: University of Chicago Press. 
Martelli, M. (1979). Un gruppo di placchette eburnee etrusche nei Musei di Bologna. Revue Archéologique, Nouvelle Série, 1, 73-86. Recuperado de: https://www.jstor.org/ stable/41747611

Martelli, M. (1985). Gli avori tardo-arcaici: botteghe e aree di diffusione. En M. Cristofani (Ed.). Il commercio etrusco arcaico. Atti dell'Incontro di studio (Roma, 1983) (pp. 207248). Roma: Consiglio Nazionale delle Ricerche.

Martelli, M. (1990). Scrigni etruschi tardo-arcaici dall'Acropoli di Atene e dall'Illiria. Prospettiva, 53-56 (1988-1989), 17-24. Recuperado de: https://www.jstor.org/ stable/24431286

Met $=$ The Pierpont Morgan Collection. Annual Report of the Trustees of the Metropolitan Museum of Art, 48 (1917), 33-39. Recuperado de: https://www.jstor.org/stable/40303361

Oenbrick, W. (2005): Halb Tier, Halb Mädchen. Sphingen in der römischen Grabplastik Typenwandel und Typenwanderung in späthellenistischer und römischer Zeit. Kölner Jahrbuch, 38, 7-89.

Petit, T. (2011). Oedipe et le Chérubin: Les sphinx levantins, cypriotes et grecs comme gardiens d'Immortalité. DOI: https://doi.org/10.5167/uzh-137865

Petit, T. (2020): Les sphinx sur la statue de Prima Porta L'apothéose d'Auguste. KTÈMA Civilisations de l'Orient, de la Grèce et de Rome antiques, 45, 236-257. Recuperado de: https://halshs.archives-ouvertes.fr/halshs-03070174

Pollak, L. (1906). Archaische Elfenbeinreliefs. Mitteilungen des Deutschen Archaeologischen Instituts, Roemische Abteilung, XXI. Roma-Berlin: W. Regenberg.

Quintero, P. (1913). Uclés, Excavaciones efectuadas en distintas épocas y noticia de algunas antigüedades. Segunda parte. Cádiz: Imprenta de Manuel Álvarez.

Renard, M. (1938). Ivoires étrusques inédits. L'Antiquité Classique, 7(2), 247-259. DOI: https://doi.org/10.3406/ antiq. 1938.3171

Renger, A. B. (2013). Oedipus and the Sphinx: The Threshold Myth from Sophocles through Freud to Cocteau. Chicago: University of Chicago Press. DOI: https://doi.org/10.7208/ chicago/9780226048116.001.0001

Richter, G. M. A. (1961). The Archaic Gravestones of Attica. London: Phaidon Press.

Rísquez, C. y Molinos, M. (2014). Necrópolis ibéricas en el FARMM. En FARMM Fondo Arqueológico Ricardo Marsal Monzón (pp. 145-153). Sevilla: Junta de Andalucía.
Rizzo, M. A. (2007). Una kotyle del pittore di Bellerofonte di Egina ed altre importazioni greche ed orientali dalla tombe 4 di Monte Abatone a Cerveteri. Bollettino d'Arte, 140, 1-56. Recuperado de: http://hdl.handle.net/11393/34931

Rodrigo, E. y Fortea, G. (2014). El recogido femenino como elemento de diferenciación social en la Grecia Clásica. En C. Alfaro, J. Ortiz y M. Antón (Eds.). Tiarae. Diadems and Headdresses in the Ancient Mediterranean Cultures: Symbolism and Technology (pp. 25-40). Valencia: Universitat de València.

Rocco, G. (1999). Avori e ossi dal Piceno. Xenia Antiqua, Monografie 7. Roma: L'Erma di Bretschneider.

Roldán, L. (1995-1996). Placas de marfil etruscas en la Península Ibérica. Anuario del Departamento de Historia y Teoría del Arte, VII-VIII, 9-23.

Sauron, M. (1990). Les monstres au coeur des conflits esthétiques à Rome au Ier siècle avant J.-C. Revue de l'Art, 90, 35-45. DOI: https://doi.org/10.3406/rvart.1990.347869

Sciacca, F. (2013). Le prime sfingi in Etruria: iconografie e contesti. En M. ${ }^{a}$ C. Biella, E. Giovanelli y L. G. Perego (Eds.). Il bestiario fantastico di età orientalizzante nella penisola italiana (pp. 239-285). Trento: Tangram.

Smoquina, E. (2013). I centauri e le sfingi nell'Etruria di età orientalizzante: tra decorazione e narrazione. En M. ${ }^{\mathrm{a}}$ C. Biella, E. Giovanelli y L. G. Perego (Eds.). Il bestiario fantastico di età orientalizzante nella penisola italiana (pp. 287-315). Trento: Tangram.

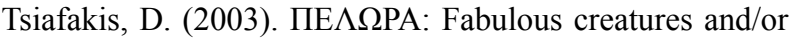
Daemons of Death. En J. M. Padgett, W. A. P. Childs y D. S. Tsiaphakē (Eds.). The Centaur's Smile: The Human Animal in Early Greek Art (pp.73-104). Princeton: Princeton University Art Museum.

Vermeule, E. (1964). Greece in the Bronze age. Chicago: University of Chicago Press.

Virgili, P. (1989). Acconciature e maquillage. Serie Vita e costumi dei romani antichi, 7. Roma: Museo della Civiltà Romana.

Vives, A. (1917). Estudios de arqueología cartaginesa. La necrópolis de Ibiza. Madrid: Imprenta de Blass y Cia.

Wiggermann, F. A. M. (1993-1997). Mischwesen. A. Philologisch Mesopotamien. Reallexikon der Assyriologie und Vorderasiatischen Archäologie, VIII, 222-246.

Wilkinson, R. H. (2003). The Complete Gods and Goddesses of Ancient Egypt. London: Thames \& Hudson. 